\title{
Nondestructive Monitoring of Structural Materials using Automated Ball Indentation (ABI) Technique
}

\author{
K. Linga Murty ${ }^{1)}$ and M.D. Mathew ${ }^{2)}$ \\ 1) North Carolina State University, Raleigh, NC 27695 USA \\ 2) Indira Gandhi Center for Atomic Research, Kalpakkam 603102 India
}

\begin{abstract}
Materials used for high temperature components in nuclear power generation, aerospace, chemical and process plants undergo changes in their microstructure during operation in service leading to degradation in their mechanical properties. Monitoring the progressive changes in the mechanical properties is very important from the point of view of ensuring the structural integrity of the components and also for possible extension of their useful service life. Nondestructive methods for directly evaluating the mechanical properties are required for the success of any materials ageing and life management program. In this paper, we describe an innovative automated technique based on ball indentation that can be used for laboratory and field applications in order to measure the mechanical and fracture properties of materials along with typical results from laboratory studies on engineering materials.
\end{abstract}

\section{INTRODUCTION}

A thorough knowledge of the material condition of various structures in nuclear plants is of prime significance for their continued safe operation. Often, the adverse conditions in the nuclear reactor such as the corrosive water environment, neutron radiation field, etc., lead to deterioration of the materials. It has been a challenge to determine the current state of the structures and intense attention has been paid in developing techniques so that the safety of the structures can be assessed.

A fully automated ball indentation (ABI) technique has been employed to determine tensile and fracture properties of ferritic steels, an austenitic stainless steel and a nickel base superalloy in different thermo-mechanical conditions. Gradients in mechanical properties of ferritic steel welds, particularly in the narrow heat-affected zone, are clearly established. A minimum in the fracture energy was noted at around $1 \mathrm{~mm}$ from the fusion line as has been shown using destructive tests.

The effect of cold-work was studied using ABI in order to simulate radiation hardening and embrittlement, and ABI data clearly revealed not only the expected hardening but also the corresponding embrittlement in terms of increased $\mathrm{RT}_{\text {NDT. }}$ Thermal aging is characterized in a cast stainless steel (CF-8) as well as a Ni-base superalloy (Alloy 625). The $\mathrm{ABI}$ data are correlated with tensile and Charpy results where applicable while in CF-8, remnant magnetization (using Squid) was also compared. This ABI technique was also found to be useful in determining the anisotropy in the tensile properties of Zircaloy cladding. Mechanical anisotropy parameters ( $\mathrm{R}$ and $\mathrm{P}$ ) determined from flow stresses along the hoop, axial and thickness directions are shown to be in agreement with the previously published data using destructive tensile and internal pressurization tests.

Practical applications of ABI include assessment of radiation embrittlement of nuclear reactor pressure vessel steels, degradation of SS piping, sensitization of BWR core shroud, etc. In addition these can also be performed in-situ by appropriate instrumentation.

\section{AUTOMATED BALL INDENTATION AND STRESS-STRAIN MICROPROBE SYSTEM}

The Stress-Strain Microprobe (SSM) was developed and patented by Advanced Technology Corporation to test minimal material, and determine key mechanical and fracture properties of metallic structures including welds and heataffected zones[1]. SSM system is based on automated ball indentation technique and involves strain-controlled multiple indentations at a single penetration location on a polished metal surface by a small spherical indenter. The applied indentation loads and the associated penetration depths are measured during the test, and are used to calculate the incremental stress-strain values from a combination of elastic and plastic analyses, and semi-empirical relationships which govern material behavior under multiaxial indentation loading. By analyzing the flow curve, tensile deformation parameters of the material such as yield strength, tensile strength, strength coefficient and strain hardening exponent as well as fracture toughness parameters like $\mathrm{K}_{\mathrm{JC}}$ and Indentation Energy to Fracture are evaluated[2-5].

Correlation of indentation hardness and indentation strain associated with a spherical indenter to uniaxial flow stress and flow strain is based on three premises[6]. (i) monotonic true stress-true plastic strain curves obtained from uniaxial tension and compression testing are reasonably similar, (ii) indentation strain correlates with true plastic strain in a uniaxial tensile test, and (iii) mean ball indentation pressure correlates with true flow stress in a uniaxial tensile test. These three premises are well established for several materials[7]. The ABI technique of loading followed by partial unloading during indentation enables a proper evaluation of indentation depth $\left(\mathrm{h}_{\mathrm{p}}\right)$ associated with plastic deformation of 
the material. The plastic diameter can then be determined from $h_{p}$ if the sinking-in and piling-up of the test material around the indentation are not pronounced[8]. Figure 1 is a photograph of the SSM used in the present study.

\section{ABI ANALYSIS}

In a standard tensile test, the uniaxial deformation is almost confined to the constant volume of the specimen's gauge section. Initially, the material is deformed elastically, following which plastic yielding and work-hardening commence, and these processes continue homogeneously till the onset of necking. In contrast, in an ABI test, the elastic and plastic deformations are not distinctly separated; both elastic and plastic deformation takes place simultaneously during the entire course of the test. With increasing indentation penetration depth, an increasing volume of test material is forced to flow under multiaxial compressive stresses generated by the advancing indenter. As shown in Fig.2, ABI load increases approximately linearly with penetration depth. The linear increase is the consequence of two non-linear but opposing processes occurring simultaneously; the non-linear increase in the applied load with penetration depth because of the spherical geometry of the indenter is offset by the power-law work hardening behavior of the test material.

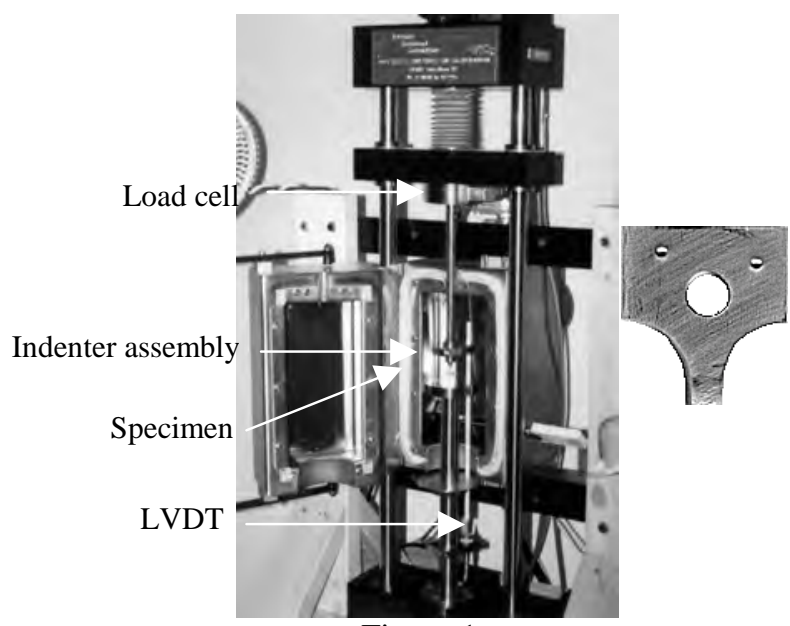

Figure 1

Photograph of SSM and indentations on specimen shoulder

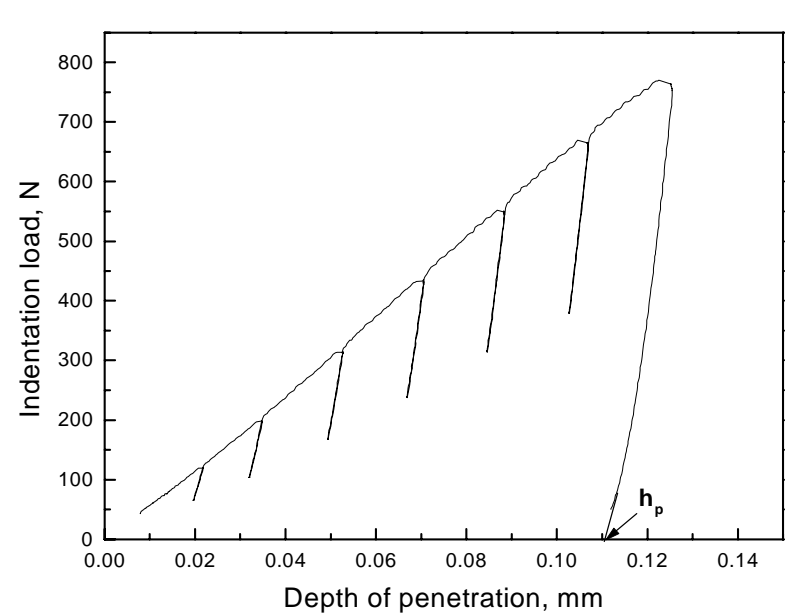

Figure 2

\section{STRESS-STRAIN RELATION}

Using the Hertzian equation [9] the plastic depth $h_{p}$, is converted into plastic indentation diameter $d_{p}$, using the equation,

$$
d_{p}=\sqrt[3]{(2.735 \text { P D }) \frac{\left[1 / E_{\text {spec }}+1 / E_{\text {ind }}\right]\left[4 h_{p}^{2}+d_{p}^{2}\right]}{4 h_{p}^{2}+d_{p}^{2}-4 h_{p} D}},
$$

where $\mathrm{P}$ is the indentation load, $\mathrm{E}_{\mathrm{spec}}$ and $\mathrm{E}_{\mathrm{ind}}$ are the elastic moduli of the specimen and the indenter respectively, and $\mathrm{D}$ is the diameter of the ball indenter. The indentation strain $\left(\mathrm{d}_{\mathrm{p}} / \mathrm{D}\right)$ is then converted into the true plastic strain $\varepsilon_{\mathrm{p}}$ in a uniaxial tensile test using the relation,

$$
\varepsilon_{\mathrm{p}}=0.2\left(\mathrm{~d}_{\mathrm{p}} / \mathrm{D}\right)
$$

The maximum strain that can be measured in an ABI test is $20 \%$ when $d_{p}=D$. The Hertz theory for normal contact between elastic solids is used for the analysis of deformation taking place at the beginning of the indentation test. Under a load $\mathrm{P}$, the mean normal pressure $\left(\mathrm{S}_{\mathrm{m}}\right)$ acting on the material is $4 \mathrm{P} / \pi \mathrm{d}_{\mathrm{t}}^{2}$ where $\mathrm{d}_{\mathrm{t}}$ is the total diameter of the impression. Using the maximum shear stress theory as yielding criterion, the uniaxial flow stress $\sigma$ is given by $\sigma=\mathrm{S}_{\mathrm{m}} / \delta$ where $\delta$ is a constraint factor. The flow stress is smaller than the mean indentation pressure because the plastic deformation of the material is constrained by the surrounding elastic material. The homogeneous portion of the plastic flow curve can be represented by the power law equation

$$
\sigma=K \varepsilon_{\mathrm{p}}{ }^{\mathrm{n}}
$$

where $\sigma$ is the true stress, $\varepsilon_{\mathrm{p}}$ is the true plastic strain, $\mathrm{n}$ is the strain hardening exponent and $\mathrm{K}$ is the strength coefficient. Values of $\mathrm{K}$ and $\mathrm{n}$ are determined by linear regression analysis of the data fitted to Eq. 3 provided the plot of the data $\mathrm{ln}$ $\sigma$ versus $\ln \varepsilon_{\mathrm{p}}$ is linear. For $\varepsilon_{\mathrm{p}}=\mathrm{n}$, Eq.3 provides the expression for true tensile strength from which the engineering value of tensile strength (UTS) is calculated. 


\section{INDENTATION ENERGY TO FRACTURE}

Elasticity theory and finite element analyses show that the stress triaxilities present at a crack tip in a fracture toughness specimen and those at the center of the contact surface under the indenter are similar[10]. The deformation energy at the center of the impression is hence comparable to that at the front of a crack tip. Therefore, the indentation energy absorbed per unit contact area up to a critical fracture stress $\sigma_{\mathrm{f}}$ (corresponding to imaginary fracture) can be related to the fracture energy of the material[11]. This parameter is referred to as Indentation Energy to Fracture ( $\left.\mathrm{W}_{\text {IEF }}\right)$, and it represents the fracture energy that is determined from ABI-measured stress-strain curves up to either the critical fracture stress or critical fracture strain, depending upon the micromechanism controlling fracture. The concept of a critical fracture stress is applied to the lower shelf and transition regions defined in a Charpy energy versus temperature relationship for a material showing typical ductile to brittle transition; the concept of a critical fracture strain is applied to the upper shelf region. The resultant expression for $\mathrm{W}_{\mathrm{IEF}}$ is shown in Eq.4,

$$
\mathrm{W}_{\text {IEF }}=\int_{0}^{\mathrm{h}_{\mathrm{f}}} \mathrm{P}_{\mathrm{m}}(\mathrm{h}) \mathrm{dh},
$$

where $h_{f}$ is the indentation depth that corresponds to the mean critical pressure. The total fracture energy per unit area can be expressed as

$$
\mathrm{W}_{\mathrm{f}}=\mathrm{W}_{\mathrm{o}}+\mathrm{W}_{\mathrm{T}} .
$$

$\mathrm{W}_{\mathrm{o}}$ is the lower shelf energy per unit area (toughness parameters such as Charpy impact energy, and static fracture toughness, $\mathrm{K}_{\mathrm{IC}}$, have non-zero lower-shelf values even at very low temperatures) and $\mathrm{W}_{\mathrm{T}}$ is the temperature-dependent energy per unit area. $\mathrm{W}_{\mathrm{T}}$ can be related to the elastic-plastic deformation and accounts for a large portion of the total fracture energy in the ductile-brittle transition region. Since $\mathrm{W}_{\mathrm{IEF}}$ includes only elastic-plastic deformation energy, it is regarded as the temperature-dependent energy term, so that

$$
\mathrm{W}_{\mathrm{f}}=\mathrm{W}_{\mathrm{o}}+\mathrm{W}_{\mathrm{IEF}}
$$

From fracture mechanics models and generalized Griffith theory, it can be shown that the fracture toughness parameter $\mathrm{K}_{\mathrm{JC}}$ can be expressed as Eq.7[12]

$$
\mathrm{K}_{\mathrm{JC}}=\left(2 \mathrm{EW}_{\mathrm{f}}\right)^{0.5} \text {. }
$$

\section{CORRELATION OF ABI-DERIVED $\sigma-\varepsilon$ CURVES WITH UNIAXIAL TENSILE CURVES}

Two examples are shown in Figure 3 demonstrating the correlation of the true $\sigma-\varepsilon$ curves derived from ABI tests and tensile data obtained from subsize miniature tensile specimens of aged cast stainless steel (CF-8) and ASTM grade A533B steel weld. The ABI data on A533B pressure vessel steel submerged arc weldment from Oak Ridge National Laboratories (ORNL) Heavy Section Steel Irradiation (HSSI) series are compared with the tensile results for the base and weld metals in Figure 3 that also illustrates a good correlation between ABI and tensile data[2]. Due to the relatively low ductility of A533B, the tensile data are at the lower end of the curve[5].

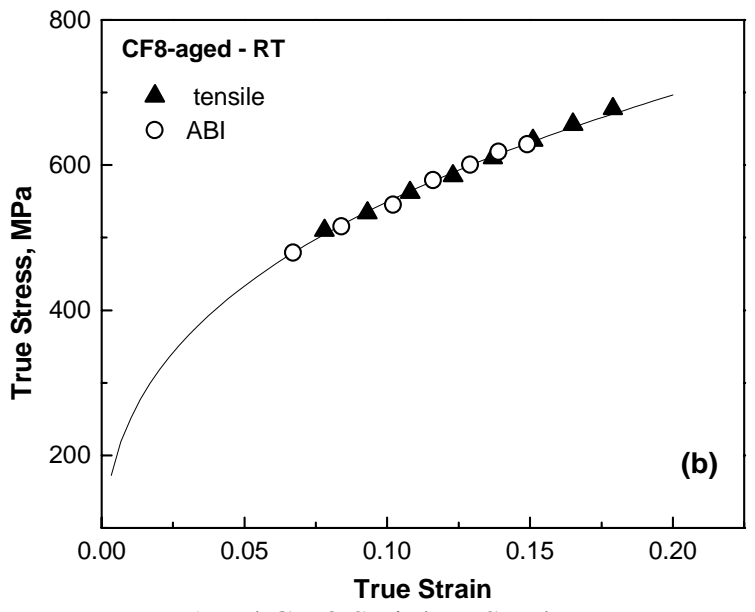

Aged CF-8 Stainless Steel

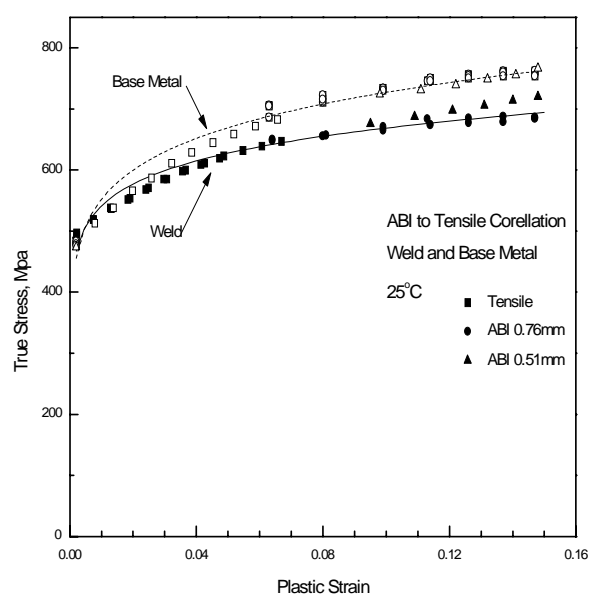

A533B steel (weld, base and HAZ)

\section{EFFECT OF COLD-WORK ON FRACTURE BEHAVIOR OF LOW ALLOY STEEL}

It is well known that ferritic steels commonly used in reactor pressure vessels and supports exhibit radiation embrittlement in terms of increased DBTT (or $\mathrm{RT}_{\mathrm{NDT}}$ ) and decreased fracture toughness. Similar effects are expected following cold-working also. We examined the influence of cold-work on mechanical and fracture characteristics of a low alloy ferritic steel of grade A36. The ABI-derived true $\sigma-\varepsilon$ curves at ambient temperature for different cold-work levels are shown in Figure 4, which clearly demonstrates the increase in yield and tensile strengths (with corresponding 
decrease in strain-hardening) with increase in percentage cold-work From tests carried out at various temperatures, the fracture toughness parameter $\left(\mathrm{K}_{\mathrm{JC}}\right)$ was evaluated using Eq.7.

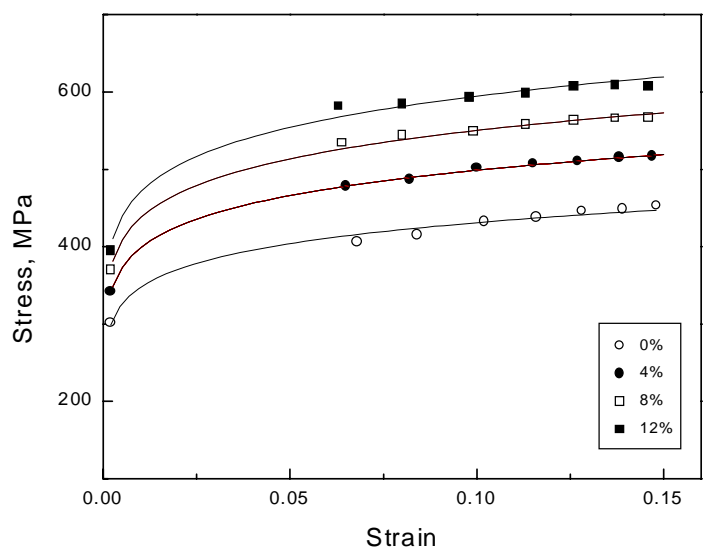

Figure 4

Effect of cold-work on true $\sigma$ - $\varepsilon$ curves (ASTM A36 grade steel)

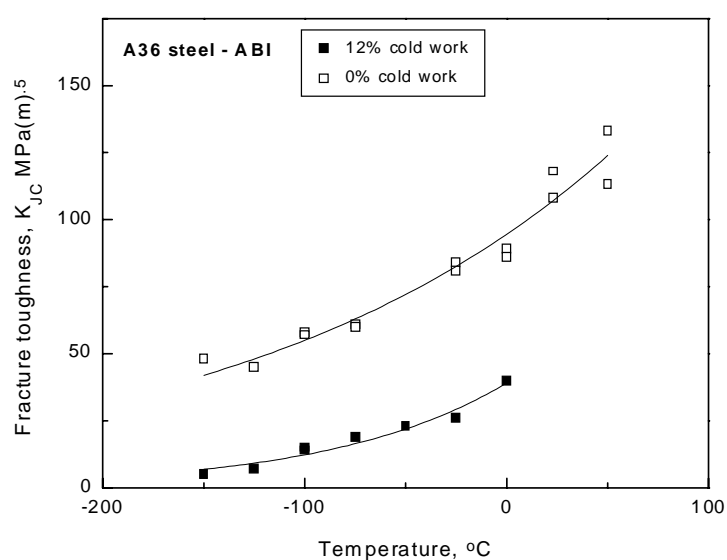

Figure 5

Variation of fracture toughness with temperature (Effect of cold-work)

Figure 5 depicts the effect of $12 \%$ cold-work in terms of decreased toughness and increased $\mathrm{RT}_{\mathrm{NDT}}$. These results clearly demonstrate the usefulness of ABI technique in characterizing the radiation embrittlement of RPV steels. The obvious advantage of ABI technique lies in the fact that even a broken Charpy bar could be used several times for evaluating the effect of radiation exposure to different fluence levels thus eliminating the need for extensive amount of surveillance material

\section{GRADIENT PROPERTIES OF RPV STEEL WELDMENTS}

The unique advantage of using ABI technique lies in the characterization of gradients in mechanical properties of steel welds (Figure 3). Gradients in the strength of the base metal, weld metal and the different microstructural zones in the heat affected zone were investigated on A533B pressure vessel steel weld prepared using submerged arc welding process (procured from Oak Ridge National Laboratories (ORNL) Heavy Section Steel Irradiation series). Figure 6 depicts the positional dependence of the strength of the weldment from base to HAZ to the weld-zone and it clearly illustrates the good correlation in the tensile properties with changes in the microstructure[2]. Corresponding changes in the IEF are illustrated in Figure 7, which indicates that the minimum in indentation energy to fracture occurred at around $1 \mathrm{~mm}$ from the fusion line. This implies that it is very important to characterize the fracture behavior of welds at positions less than $1 \mathrm{~mm}$ from the fusion line.

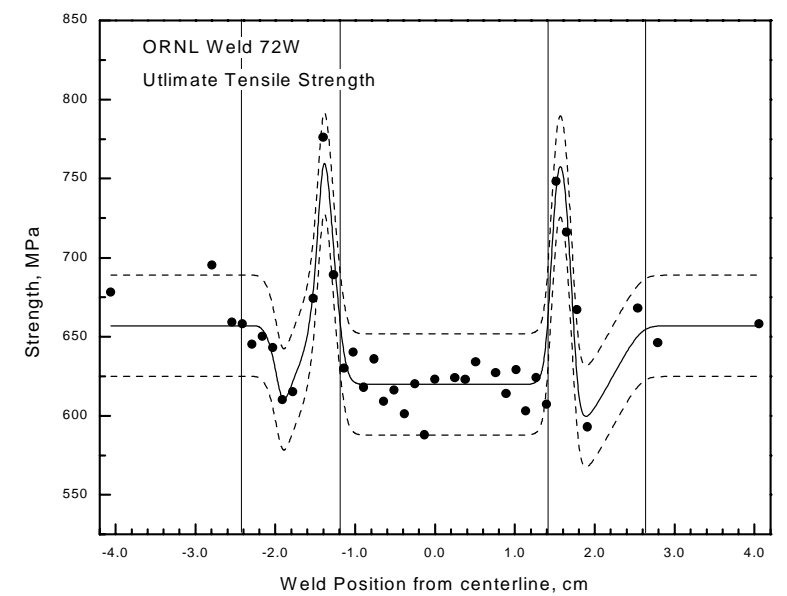

Figure 6

Variation of UTS with position

(base - HAZ - weld metal - HAZ - base)

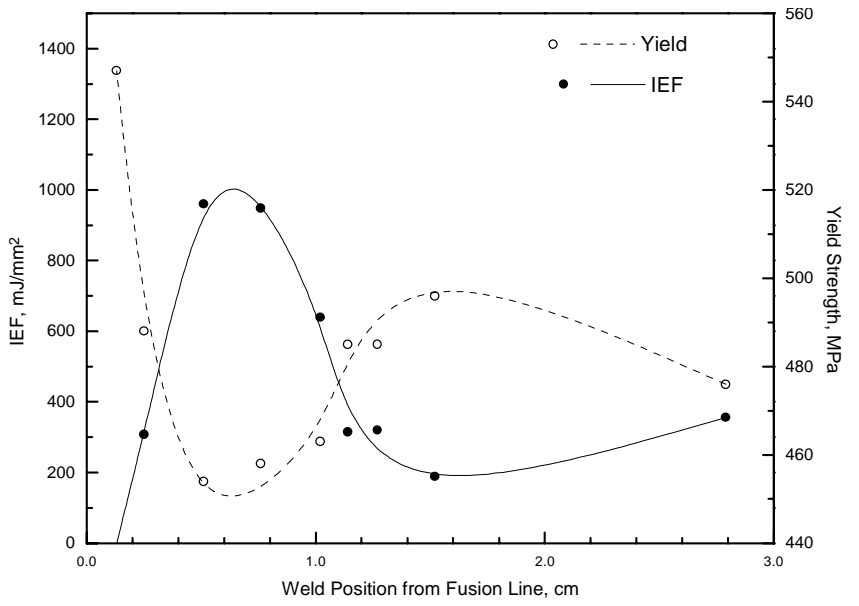

Figure 7

Variation of IEF with position (from weld fusion line through HAZ and base)

The temperature variations of IEF in different zones is shown in Figure 8 that depict the typical ductile to brittle transition as higher temperatures are encountered. The upper shelf energies exhibited distinct differences between the base metal, weld and HAZ. Similarly, the DBTT is also different which increased from weld to base metal to HAZ. The results clearly indicated the inferiority of the HAZ compared to both the base and weld metals. 


\section{MECHANICAL ANISOTROPY OF TEXTURED ZIRCALOY}

Zirconium alloys are commonly used in thermal reactors for fuel cladding, intermediate grids, channels (BWRs), pressure and calandria tubes (PHWRs). Zircaloys (zirconium alloyed primarily with tin, iron and nickel) have hexagonal close packed crystal (hcp) structure at the reactor operating temperatures[13]. Their hcp structure along with limited number of slip systems lead to nonrandom distribution of grain orientations or textures that in turn make these materials highly anisotropic thereby exhibiting direction dependent properties. Due to the relatively small thickness of the tubing, it has been a challenge to determine the mechanical properties along the three orthogonal directions (axial ( $\mathrm{z}$ ), hoop (theta) and radial (r)) of Zircaloy tubes. The ball indentation technique has been used to determine the true $\sigma$ versus true $\varepsilon$ curves along the three directions. Figure 9 shows the stress-strain curves in the three directions, which clearly depict the anisotropic nature of the mechanical properties of thin-walled Zircaloy tubing.

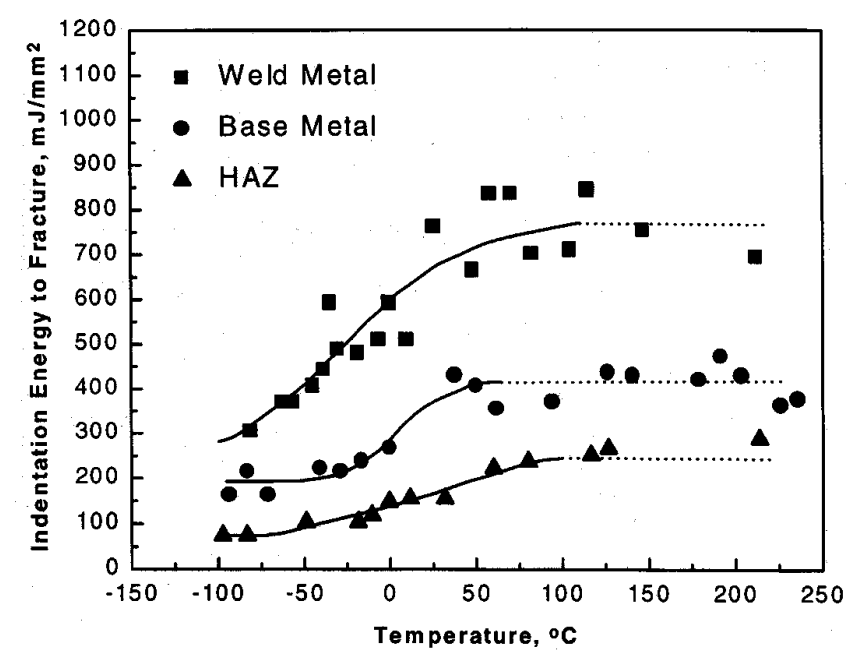

Figure 8

Variation of IEF with temperature for base, HAZ and weld metal

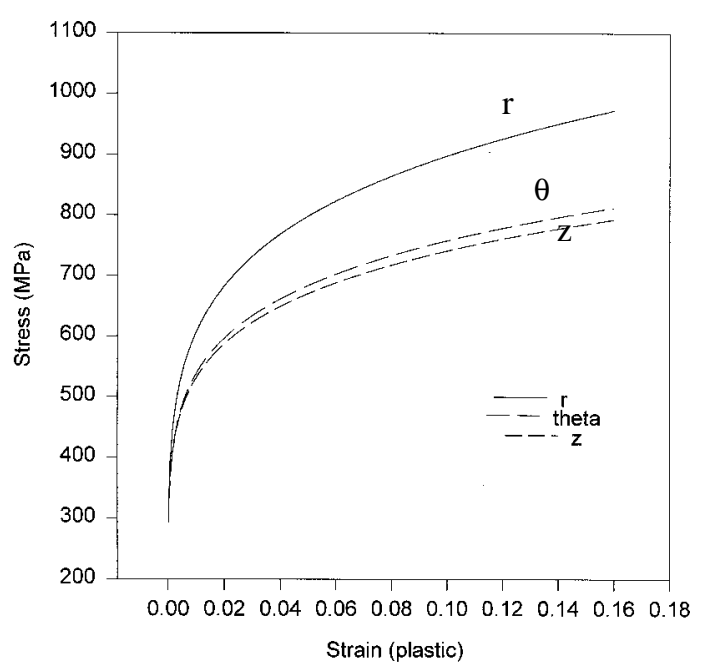

Figure 9

$\sigma-\varepsilon$ curves for Zircaloy tubing along thickness (r), hoop $(\theta)$ and axial directions

The radial or thickness direction is the strongest while axial and hoop directions seem to be of roughly equal strength. This is a reflection of the fact that the c-axis of the crystallites is close to the radial direction (at $+/-30^{\circ}$ towards hoop). The true tensile strengths are noted to be $Y_{r}=983 \mathrm{MPa}, \mathrm{Y}_{\theta}=804 \mathrm{MPa}$ and $\mathrm{Y}_{\mathrm{Z}}=782 \mathrm{MPa}$. Using these values, the anisotropy parameters $\mathrm{R}$ and $\mathrm{P}$ are derived using the following equations [15].

$$
\mathrm{R}=\frac{\left(\mathrm{Y}_{\mathrm{r}} \mathrm{Y}_{\mathrm{Z}}\right)^{2}+\left(\mathrm{Y}_{\mathrm{r}} \mathrm{Y}_{\theta}\right)^{2}-\left(\mathrm{Y}_{\mathrm{Z}} \mathrm{Y}_{\theta}\right)^{2}}{\left(\mathrm{Y}_{\theta} \mathrm{Y}_{\mathrm{Z}}\right)^{2}+\left(\mathrm{Y}_{\mathrm{r}} \mathrm{Y}_{\theta}\right)^{2}-\left(\mathrm{Y}_{\mathrm{Z}} \mathrm{Y}_{\mathrm{r}}\right)^{2}}=1.912
$$

and

$$
\mathrm{P}=\frac{\left(\mathrm{Y}_{\mathrm{r}} \mathrm{Y}_{\mathrm{Z}}\right)^{2}+\left(\mathrm{Y}_{\mathrm{r}} \mathrm{Y}_{\theta}\right)^{2}-\left(\mathrm{Y}_{\mathrm{Z}} \mathrm{Y}_{\theta}\right)^{2}}{\left(\mathrm{Y}_{\theta} \mathrm{Y}_{\mathrm{Z}}\right)^{2}+\left(\mathrm{Y}_{\mathrm{r}} \mathrm{Y}_{\mathrm{Z}}\right)^{2}-\left(\mathrm{Y}_{\theta} \mathrm{Y}_{\mathrm{r}}\right)^{2}}=2.268
$$

These values for $\mathrm{R}$ and $\mathrm{P}$ are similar to what have been reported from uniaxial tensile and biaxial internal pressurization tests $[14,15]$.

\section{THERMAL AGING EFFECTS}

\section{Cast Stainless Steel (CF-8)}

Cast stainless steels such as CF-8 and CF-8M are used in nuclear power plants for several components like pump and valve casings, elbows, fittings and primary coolant pipes. CF-8 stainless steel has a duplex microstructure consisting of austenite and about $15-20 \%$ delta-ferrite. Long term exposure at the reactor operating temperatures upto $573 \mathrm{~K}$ results in aging induced embrittlement of the material due to spinodal decomposition of the ferrite phase. Mathew et al[3] reported the effects of low temperature aging at $673 \mathrm{~K}$ up to 18 months on the mechanical and fracture properties of cast CF-8 stainless steel in the range of 173-423 K. The variation of Indentation Energy to Fracture $\mathrm{W}_{\text {IEF }}$ derived from ABI tests (using a value of $1200 \mathrm{MPa}$ for $\sigma_{\mathrm{f}}$ ) with test temperature is shown in Figure 10 for the unaged and aged materials. The curves exhibit brittle fracture at low temperatures with transition to ductile behavior at higher temperatures (similar to typical impact energy versus temperature curves). $\mathrm{W}_{\mathrm{IEF}}$ decreased and $\mathrm{RT}_{\mathrm{NDT}}$ showed an upward shift with increase in aging time which tend to saturate at longer aging times just as it was observed in the case of the variation of yield strength, tensile strength, microhardness and Charpy energy[3]. The effect of aging time on $\mathrm{RT}_{\mathrm{NDT}}$ corresponding to an 
IEF value of $1500 \mathrm{mj} / \mathrm{mm}^{2}$ is illustrated in Figure 11, which clearly depicts the embrittlement in terms of, increased reference temperature leading to saturation at aging times of around 12500 hours. Although the absolute values of toughness and $\mathrm{RT}_{\mathrm{NDT}}$ could not be derived, $\mathrm{ABI}$ tests did demonstrate that it is a very sensitive technique to assess the relative changes in mechanical and fracture properties due to aging of cast SS components. Standard Charpy and tensile tests carried out to complement the ball indentation data did exhibit similar increase in strength and decrease in toughness following aging with saturation on aging for more than 12 months. Figure 12 depicts the effect of aging on temperature variation of Charpy impact energy while the correlation between IEF and $C_{V}$ is shown in Figure 13.

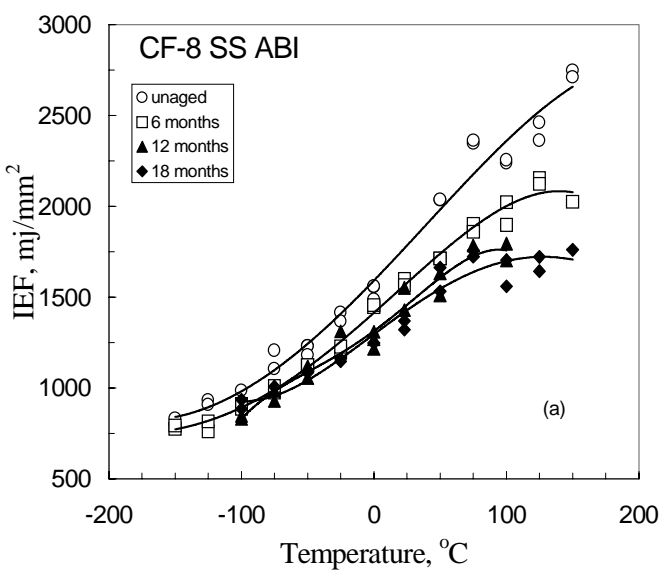

Figure 10

Variation of IEF with temperature

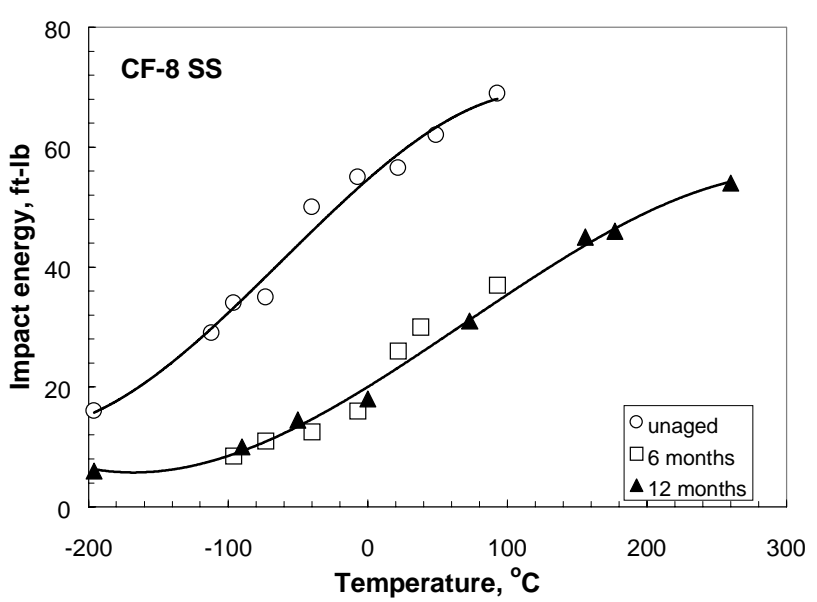

Figure 12

Effect of aging on Charpy energy

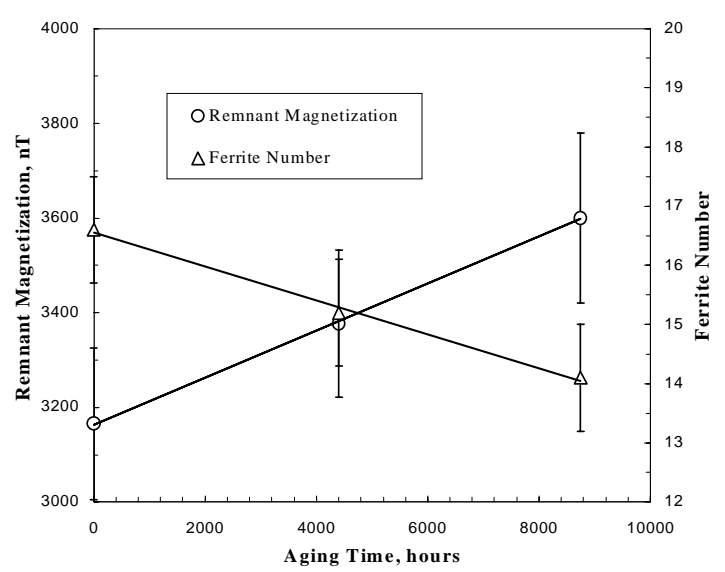

Figure 14

Effect of aging on remnant magnetization

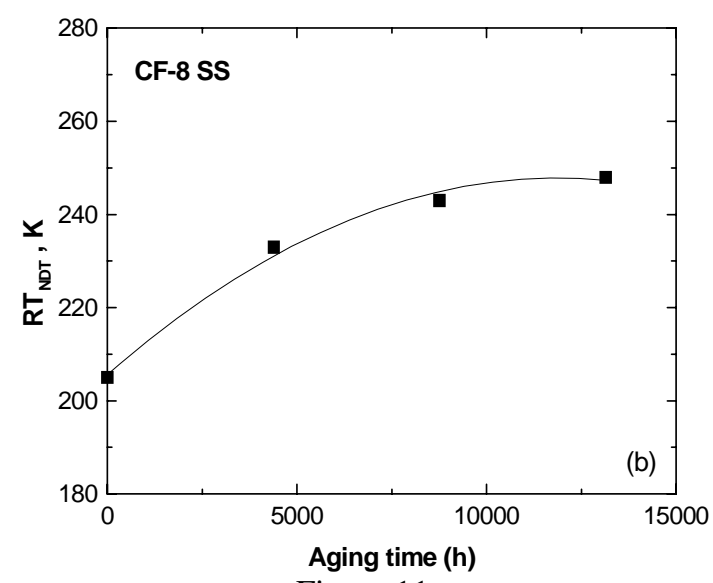

Figure 11

Variation of $\mathrm{RT}_{\mathrm{NDT}}$ with aging time

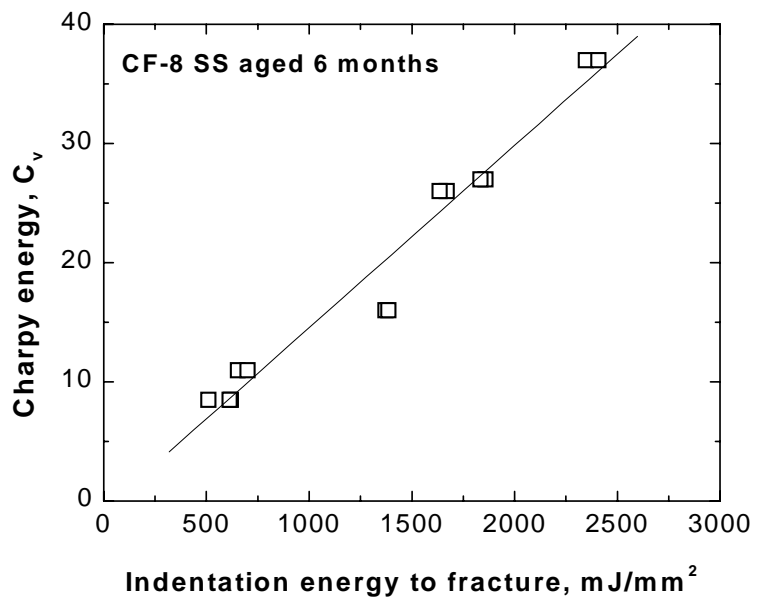

Figure 13

Correlation of ABI (IEF) and Charpy $\left(\mathrm{C}_{\mathrm{V}}\right)$

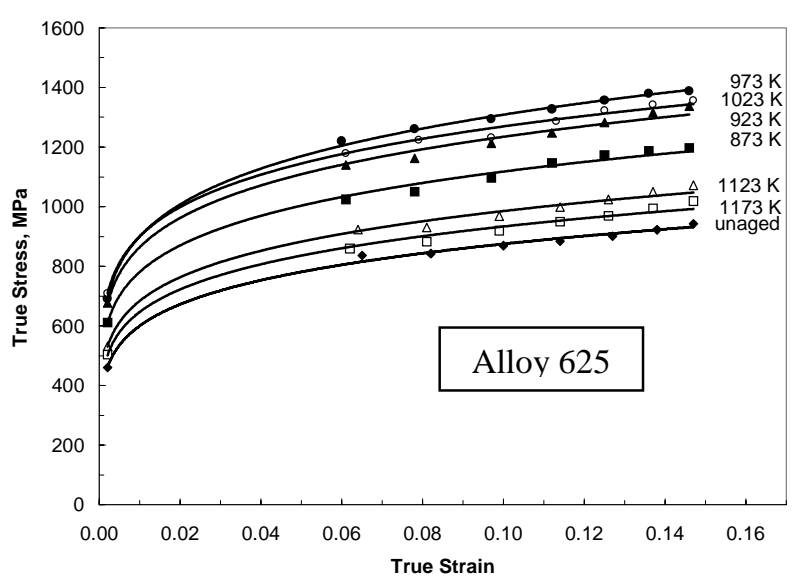

Figure 15

Effect of aging on room-temperature $\sigma-\varepsilon$ curves

While no gross changes in the delta-ferrite morphology are observed due to aging, Ferritescope measurements indicated decreased amounts of delta-ferrite with increase in aging time (Figure 14) with ferrite number decreasing from 
16.6 in the as-received material to 14.1 following 12-months aging.. The change in ferrite content was also measured using Superconducting Quantum Interference Device (SQUID) that relates the remnant magnetization of the material to the presence of aging induced precipitates. Figure 14 shows that the remnant magnetization increases linearly with increase in aging time while the amounts of delta-ferrite decrease. The presence of spinodally decomposed precipitates in ferrite prevents rotation of the magnetic domains and hence remnant magnetization increases with increase in aging time.

\section{Ni-based Superalloy 625}

The effect of thermal aging on a nickel base superalloy 625 was studied following 500 hours of aging at temperatures ranging from $873 \mathrm{~K}$ to $1173 \mathrm{~K}$. Figure 15 depicts the room temperature $\sigma-\varepsilon$ curves derived from ABI tests following aging at varied temperatures. Similar ABI test results obtained at $473 \mathrm{~K}$ are shown in Figure 16 . The variation of yield and ultimate tensile strengths with aging temperature exhibited a peak in strength following aging at $973 \mathrm{~K}$. Figure 17 includes the aging temperature variation of yield strength at $296 \mathrm{~K}$ and $473 \mathrm{~K}$ indicating such peaks. Similar behavior was noted for the strength as well.

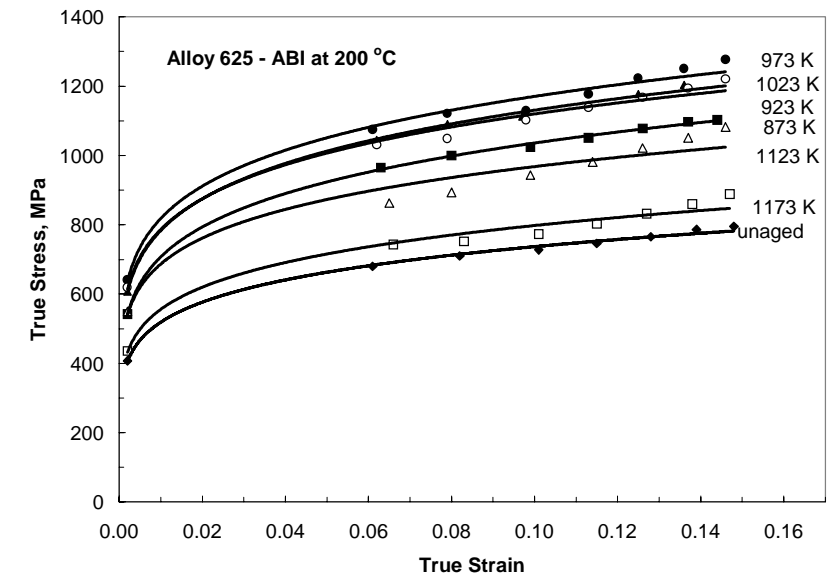

Figure 16

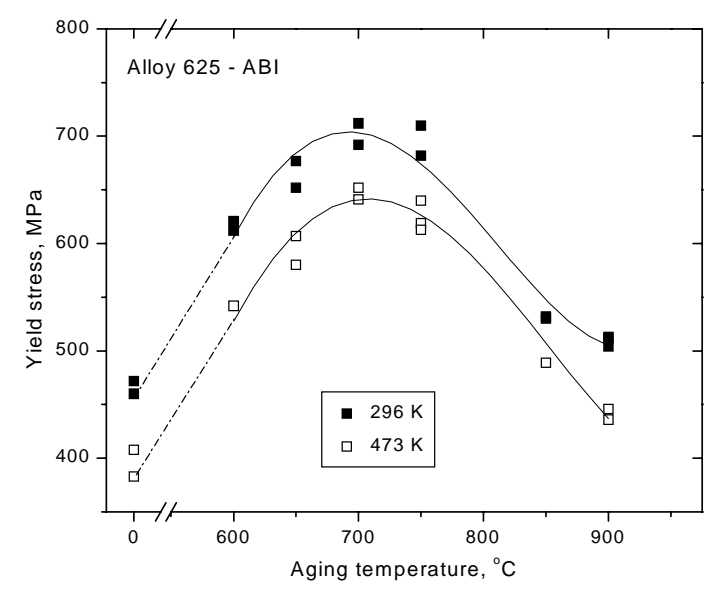

Figure 17

Variation of yield strength on aging temperature

Effect of aging $\sigma-\varepsilon$ curves at $473 \mathrm{~K}$

Microstructure of the aged samples has been studied using scanning electron microscope (SEM). The samples were given electrolytic etching using chromic acid to reveal the carbides and intermetallic phases. Figures $18 \mathrm{a}$ through $4 \mathrm{f}$ show the microstructure of Alloy 625 aged at various temperatures. Above $973 \mathrm{~K}$, needle shaped precipitates have been observed in the matrix. Maximum precipitation was observed at $1073 \mathrm{~K}$ and the density of these precipitates decreased at higher aging temperatures. At $1173 \mathrm{~K}$, there was a sharp decrease in the density and an increase in the size of the acicular precipitates. Although Alloy 625 was originally developed as a solid solution strengthened material, the material is known to be microstructurally unstable at elevated temperatures[16]. Carbides of type $\mathrm{MC}, \mathrm{M}_{6} \mathrm{C}$, $\mathrm{M}_{23} \mathrm{C}_{6}$, and intermetallic phases $\left(\gamma^{\prime \prime}\right.$ and $\delta$ ) precipitate in this alloy depending upon the temperature and duration of ageing. $\gamma^{\prime \prime}$ is a metastable phase with an ordered body centred tetragonal $\mathrm{DO}_{22}$ crystal structure of $\mathrm{Ni}_{3}(\mathrm{Nb}, \mathrm{Ti}, \mathrm{Al})$ composition. The equilibrium intermetallic precipitate is the $\delta$ phase. It has an orthorhombic crystal structure with composition $\mathrm{Ni}_{3} \mathrm{Nb}$.

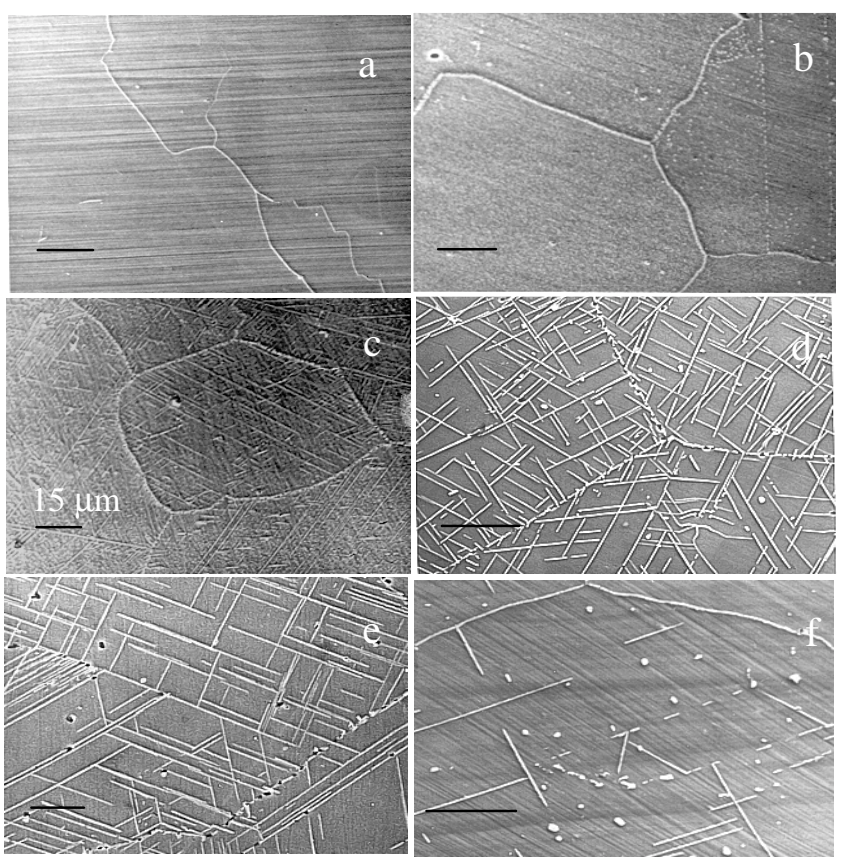

Figure 18

Microstructure of alloy 625 after aging at (a) $873 \mathrm{~K}$, (b) $973 \mathrm{~K}$, (c) $1023 \mathrm{~K}$, (d) $1073 \mathrm{~K}$, (e) $1123 \mathrm{~K}$ and (f) $1173 \mathrm{~K}$

Based on the observed morphology (Fig.18), the needle shaped precipitates are presumed to be $\delta$-phase. Although precipitates were not observed in SEM studies of material at and below $973 \mathrm{~K}$, it is well established[16] that fine precipitates of $\gamma^{\prime \prime}$, which is a metastable phase with an ordered body centred tetragonal structure of $\mathrm{Ni}{ }_{3}(\mathrm{Nb}, \mathrm{Ti}, \mathrm{Al})$ composition, form in the temperature range of $873 \mathrm{~K}$ to about $1000 \mathrm{~K}$. Transmission Electron Microscopy (TEM) was 
carried out on material aged at $973 \mathrm{~K}$, and $\gamma^{\prime \prime}$ precipitates with typical disc shaped morphology were observed (Figure 19). Although extensive TEM studies were not performed at other ageing conditions, it is suggested, based on published literature[16] and the current TEM study, that $\gamma^{\prime \prime}$ precipitates of increasing size and density are present in the aged material.

\section{SUMMARY}

Automated Ball Indentation is shown to be a promising technique for monitoring the material condition of structures and components so that their life assessment and life extension could be carried out nondestructively. With appropriate design modifications, the Stress Strain Microprobe can be adapted for in-situ determination of mechanical properties of materials of various kinds of components. For example, one could attach the machine to the pipe by mechanical means; a welded pair of stainless steel pipes was examined for circumferential weld uniformity[17]. Another possible application is on the nondestructive evaluation of radiation embrittlement of pressure vessels in operating nuclear reactors by in-situ monitoring using magnetic attachments. It should be pointed out that SSM is useful in addition, to characterize other structures such as encountered in die-attachments in microelectronics[18], to investigate deformation and creep characteristics[19,20] of various metallic and non-metallic materials.

\section{REFERENCES}

1. F.M. Haggag, Field Indentation Microprobe for Structural Integrity Evaluation, U.S. Patent No. 4,852,397, August $1,1989$.

2. K.L.Murty, P.Q.Miraglia, M.D.Mathew, V.N.Shah and F.M.Haggag, Int. J. Pressure Vessels and Piping, 76(1999) 361-369.

3. M.D.Mathew, L.M.Lietzan, K.L.Murty and V.N.Shah, Mater. Sci. \& Engg., 269 (1999) 186-196.

4. M.D.Mathew, K.L.Murty, K.B.S.Rao and S.L.Mannan, Mater. Sci. \& Engg, A264(1999) 159-166.

5. K.L.Murty, M.D.Mathew, Y.Wang, V.N.Shah and F.M.Haggag, Int. J. Pressure Vessels and Piping, 75(1998) 831840.

6. D. Tabor, The Hardness of Metals, Oxford University Press, New York (1951).

7. F.M. Haggag in Small specimen Test Technique Applied to Nuclear Reactor Pressure Vessel Thermal Annealing and Plant Life Extension, ASTM STP 1024, W.R. Corwin, F.M. Haggag and W.L. Server (eds.), ASTM, Philadelphia, PA, 1993, p.27.

8. C.H. Mok, Exp. Mechanics (1966) 87.

9. F.M. Haggag and R.K. Nanstad in Innovative Approaches to Irradiation Damage and Failure Analysis, D.L. Marriot, T.R. Mager and W.H. Bamford (eds.), ASME PVP Vol. 170, ASME, New York, 1989, p.101.

10. T.S. Byun, J.W. Kim and J.H. Hong, J. Nucl. Mater., 252 (1998) 187.

11. F.M. Haggag, T.S. Byun, J.H. Hong, P.Q. Miraglia and K.L. Murty, Scr. Mater., 38(1998) 645.

12. T.L. Anderson in Fracture Mechanics, CRC Press Inc., Boca Raton, FL, USA, 1995, p.41.

13. K.L. Murty, Materials Forum, Institute of Metals and Materials Australasia Ltd., 15, (1991) pp. 217 - 230.

14. K.L. Murty, in Textures in Materials Research, R.K. Ray and A.K. Singh (Eds.), Oxford \& IBH Publishing Co., Ltd. New Delhi (1999) pp. 113-160.

15. K.L. Murty, Creep Studies for Life-Prediction in Water Reactors, Journal of Metals, Oct. 1999, pp. 32-39.

16. L. Ferrer, B.Pieraggi and J.F.Uginet, Superalloys 718, 625 and Various Derivatives, E. E Loria (ed.), The Minerals, Metals and Materials Society (1991) p.217.

17. F.M. Haggag and K.L. Murty, Proceedings of Nondestructive Evaluation (NDE) and Materials Properties III, TMS (1997) pp. $101-106$.

18. K.L. Murty and F.M. Haggag, Application to Solder Aging and Life Prediction," EEP-Vol. 19-1, Advances in Electronic Packaging - June, 1997, ASME (1997) pp. 1133 - 1139.

19. M.D. Mathew and K.L. Murty, J. Mater. Sci., vol. 34 (1999) pp. 1497-1503.

20. M.D. Mathew, S. Movva, H. Yang and K.L. Murty, in Proceedings of TMS Symposium on 'Creep Behavior of Advanced Materials for the $21^{\text {st }}$ Century,' R.S. Mishra, A.K. Mukherjee and K.Linga Murty (eds.) TMS (1999) pp. 51-60. 